This document is the Accepted Manuscript version of a Published Work that appeared in final form in The Journal of Organic Chemistry, copyright (C) American Chemical Society after peer review and technical editing by the publisher.

To access the final edited and published work see https://x.doi.org/10.1021/acs.joc.9b01427 


\title{
Incorporating Morpholine and Oxetane into Benzimidazolequinone Anti-Tumour Agents: The Discovery of 1,4,6,9-Tetramethoxyphenazine from Hydrogen Peroxide and Hydroiodic Acid-Mediated Oxidative Cy- clizations
}

\author{
Darren Conboy, ${ }^{\dagger}$ Styliana I. Mirallai, $₫$ Austin Craig,$\$$ Patrick McArdle $\$$ Ali A. Al-Kinani, ${ }^{\ddagger}$ Stephen \\ Barton, ${ }^{\dagger}$ and Fawaz Aldabbagh ${ }^{*}+, \AA, \S$ \\ †Department of Pharmacy, School of Life Sciences, Pharmacy and Chemistry, Kingston University, Penrhyn Road, \\ Kingston upon Thames, KT1 2EE, UK. \\ \$School of Chemistry, National University of Ireland Galway, University Road, Galway, H91 TK33, Ireland.
}

\begin{abstract}
The reactivity of hydrogen peroxide and catalytic hydroiodic acid towards 3,6-dimethoxy-2-(cycloamino)anilines is tunable to give ring-fused benzimidazoles or 1,4,6,9-tetramethoxyphenazine in high yield. Mechanisms via a detected nitroso-intermediate are proposed for oxidative cyclization and the unexpected intermolecular displacement of the oxazine. An aqueous solution of molecular iodine is capable of the same transformations. Oxidative demethylation gave targeted benzimidazolequinones, including without cleavage of the incorporated oxetane.
\end{abstract}

Morpholine is prevalent in marketed drugs. ${ }^{1}$ The replacement of functional groups with morpholine can increase metabolic stability and hydrophilicity.2,3 Oxetane is a cyclic ether with similar hydrogen bonding avidity to morpholine, which has emerged as a polar alternative to the gem-dimethyl group in medicinal chemistry. ${ }^{4,5} \mathrm{NAD}(\mathrm{P}) \mathrm{H}$ :quinone oxidoreductase 1 (NQ01) is a reductase over-expressed in many solid tumours.6,7 Benzimidazolequinones are reported excellent substrates for NQ01, which was demonstrated using recombinant human NQ01.8 Computational docking has shown that a polar group (e.g. cyclic ether) four or five bonds away from the quinone functional group can lead to more efficient NQ01 binding. ${ }^{9}$ This led us to target morpholine and spirocyclic oxetane ring-fused benzimidazolequinones $\mathbf{1}$ and $\mathbf{2}$ (Figure 1).

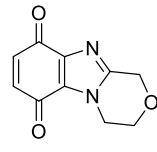

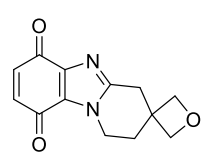

2
Figure 1. Synthetic targets.

Hydrogen peroxide is a cheap, low molar mass, odorless, and eco-friendly oxidant with high atom economy. $\mathrm{H}_{2} \mathrm{O}_{2}$ is an established mediator for the oxidative cyclization of $o$ cyclic amine substituted anilines to give ring-fused benzimidazoles. ${ }^{10-15}$ We have shown that when $\mathrm{H}_{2} \mathrm{O}_{2}$ is combined with $\mathrm{HX}$ (where $\mathrm{X}=\mathrm{Cl}$ or $\mathrm{Br}$ ), the oxidative cyclization can be accompanied by a selective aromatic halogenation in one-pot. 13 When the same $\mathrm{H}_{2} \mathrm{O}_{2}$ and $\mathrm{HX}$ system was applied to 3,6-dimethoxy-2-(cycloamino)anilines, a tunable one-pot transformation was established (Scheme 1(b)). ${ }^{15}$

Scheme $1 . \mathrm{H}_{2} \mathrm{O}_{2}$ and $\mathrm{HX}$-Mediated Transformations.

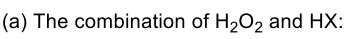

(a) The combination of $\mathrm{H}_{2} \mathrm{O}_{2}$ and $\mathrm{HX}$ :

(b) Previous work $(\mathrm{X}=\mathrm{Cl}, \mathrm{Br}):^{15}$

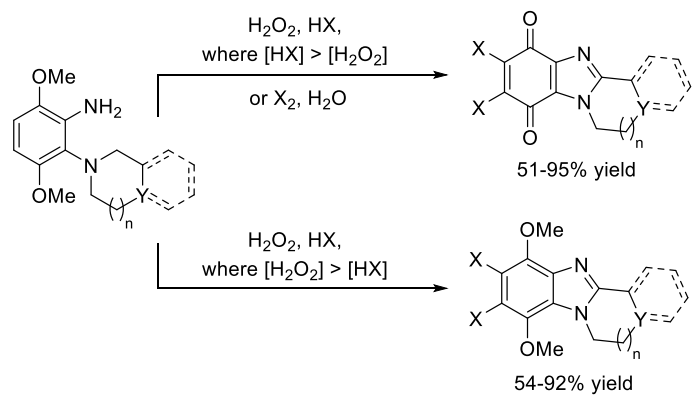

(c) This work:

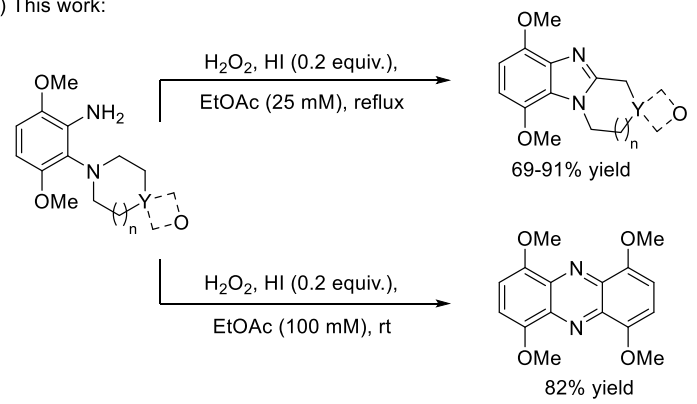

A higher molar ratio of $\mathrm{H}_{2} \mathrm{O}_{2}$ relative to $\mathrm{HX}$ resulted in halogenation and oxidative cyclization, while lower relative amounts of $\mathrm{H}_{2} \mathrm{O}_{2}$ to $\mathrm{HX}$ mediated one-pot halogenation, cyclization and quinone formation, generating halogenated ring-fused benzimidazolequinones. A larger proportion of the hydrohalic acid relative to hydrogen peroxide favors halogen $\left(\mathrm{X}_{2}\right)$ formation (Scheme 1(a)), and molecular chlorine and bromine in water were shown to independently mediate the six-electron oxidative transformation to give the halogenated ring-fused benzimidazolequinones. The 
use of hydroiodic acid (HI) is preferred over the other hydrohalic acids for the synthesis of targets $\mathbf{1}$ and $\mathbf{2}$, since the oxidative cyclization is more likely to occur without halogenation, as the electrophilicity of the halogens decreases from $\mathrm{Cl}_{2}>\mathrm{Br}_{2}>\mathrm{I}_{2 .}{ }^{16}$ Herein, the reactivity of 3,6-dimethoxy-2(cycloamino)anilines using $\mathrm{H}_{2} \mathrm{O}_{2}$ and a catalytic amount of $\mathrm{HI}$ in ethyl acetate is shown to be tunable to favor either the intramolecular reaction to give ring-fused benzimidazoles or the unexpected intermolecular reaction to give $1,4,6,9$ tetramethoxyphenazine (Scheme 1 (c)).

The four-step synthesis of ring-fused benzimidazolequinones $\mathbf{1}$ and $\mathbf{2}$ began with nucleophilic aromatic substitution $\left(\mathrm{S}_{\mathrm{N}} \mathrm{Ar}\right)$ of morpholine and 2-oxa-7-azaspiro[3.5] nonane ${ }^{17}$ onto 1,4-dimethoxy-2,3-dinitrobenzene. The substitution using bis(2-oxa-7-azaspiro[3.5]nonan-7-ium) ethanedioate gave 7-(3,6-dimethoxy-2-nitrophenyl)-2-oxa-7azaspiro[3.5] nonane (3) in 68\% yield, when using $\mathrm{K}_{2} \mathrm{CO}_{3}(4$ equiv) in a 5:1 acetonitrile:water mixture (Scheme 2). Reduction of nitrobenzenes with iron powder gave the aniline oxidative cyclization precursors in high yields with 3,6-dimethoxy-2-(2-oxa-7-azaspiro[3.5]nonan-7-yl)aniline (4b) formed in $80 \%$ yield.

Scheme 2. Preparation of 3,6-Dimethoxy-2-(2-oxa-7azaspiro[3.5]nonan-7-yl)aniline (4b).

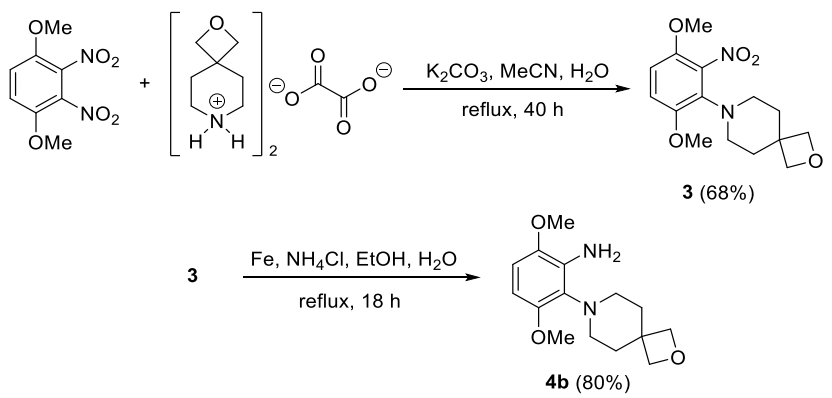

With 3,6-dimethoxy-2-(morpholin-4-yl)aniline (4a) ${ }^{15}$ and spirocyclic oxetane analogue $\mathbf{4 b}$ in hand, the oxidative cyclization using $\mathrm{H}_{2} \mathrm{O}_{2}$ and $\mathrm{HI}$ was investigated (Table 1). In keeping with the principles of green chemistry, ethyl acetate was chosen as the reaction solvent. ${ }^{14,18}$ Morpholine 4a did not undergo any transformation in EtOAc at reflux in the presence of $\mathrm{H}_{2} \mathrm{O}_{2}$ (20 equiv) alone. Addition of one stoichiometric equivalent of HI gave after 1 hour, 6,9-dimethoxy3,4-dihydro-1 $H$-[1,4] oxazino[4,3-a]benzimidazole (5a) in $56 \%$ yield along with an unexpected orange precipitate. Spectroscopic data identified the precipitate as 1,4,6,9-tetramethoxyphenazine (6), formed in 25\% yield. Using less than stoichiometric amounts of $\mathrm{HI}(0.2$ equiv), increased the yield of the desired benzimidazole 5a to 69\%, and less phenazine 6 formed in 19\% yield. Using these conditions on substrate $\mathbf{4 b}$ gave spirocyclic oxetane ring-fused benzimidazole $\mathbf{5 b}$ in $74 \%$ yield with $11 \%$ phenazine $\mathbf{6}$ formed. The amount of phenazine 6 (12\% yield) was consistent for other six-membered cyclizations, as demonstrated by conversion of 3,6-dimethoxy-2-(piperidin-1-yl)aniline (4c) to give 6,9dimethoxy-1,2,3,4-tetrahydropyrido[1,2-a]benzimidazole (5c) in $72 \%$ yield. Variation of ring-sizes was investigated, with the five- and seven-membered cyclizations of 3,6-dimethoxy-(2-pyrrolidin-1-yl)aniline (4d) and 2-(azepan-1yl)-3,6-dimethoxyaniline (4e) proceeding in high yield to respectively give 5,8-dimethoxy-2,3-dihydro- $1 H$-pyrrolo[1,2-a] benzimidazole (5d) and 1,4-dimethoxy-7,8,9,10tetrahydro-6H-azepino[1,2-a] benzimidazole (5e) in $89 \%$ and $91 \%$ yield. The absence of phenazine 6 from the latter reactions is consistent with previous observations of sixmembered oxidative cyclizations being more difficult than those forming five and expanded ring-fused benzimidazole analogues. ${ }^{14}$ For all reactions, chromatography was not required, with residues triturated in diethyl ether to afford benzimidazoles 5a-5e.

Phenazine is the scaffold of secondary metabolites from Pseudomonas and Streptomyces with many natural and unnatural examples having potent biological activity, notably anti-cancer. ${ }^{19,20}$ The oldest synthesis is the Wohl-Aue reaction, ${ }^{21}$ which is known to be low-yielding, and reported to give 1,4,6,9-tetramethoxyphenazine (6) in 10\% yield using potassium hydroxide in benzene (Scheme 3). ${ }^{22} \mathrm{We}$ attempted to improve this condensation of the aniline with nitrobenzene by using potassium tert-butoxide as base in toluene,23 but the yield of 6 remained low, at 34\%. We set about establishing a more facile route to 6 through manipulation of the optimized $\mathrm{H}_{2} \mathrm{O}_{2}$ and $\mathrm{HI}$-mediated oxidative cyclization conditions for morpholine $\mathbf{4 a}$ (Table 1). Given that phenazine $\mathbf{6}$ formation is an intermolecular reaction, it seemed plausible that the use of more concentrated conditions (less ethyl acetate) would lead to increased yields of 6 . This was indeed the case when reducing the amount of solvent by 4 -fold, phenazine 6 became the major product in $47 \%$ yield with benzimidazole $\mathbf{5 a}$ formed in $28 \%$ yield. The $\mathrm{H}_{2} \mathrm{O}_{2}$ and $\mathrm{HI}-$ mediated cyclization seemed to give the thermodynamic product, since the yield of cyclized benzimidazole $\mathbf{5 a}$ became increasingly insignificant (4\% then $2 \%$ ), when reducing the reaction temperature from reflux to 40 ${ }^{\circ} \mathrm{C}$ to room temperature with phenazine $\mathbf{6}$ isolated in excellentyield of $82 \%$. The requirement for higher temperatures for the cyclization may also be due to the nature of the oxidizing system, although hypoiodous acid (HOI) is formed, the mediating oxidant is unknown. ${ }^{24,25}$

Phenazine 6 was not formed when replacing HI (0.2 equiv) with $\mathrm{HCl}(0.2$ equiv) (Scheme $4(\mathrm{a})$ ). Under these conditions mainly recovered $\mathbf{4 a}$ was observed with 4-chloro-3,6-dimethoxy-2-(morpholin-4-yl)aniline (4f) formed in $17 \%$ yield. The regioselectivity of the chlorination was confirmed by X-ray crystallography (Scheme 4(b) and Figure S1). The yield of chlorinated aniline $\mathbf{4 f}$ increased to $76 \%$ through use of a stoichiometric equivalent of $\mathrm{HCl}$ with $\mathrm{H}_{2} \mathrm{O}_{2}$. The greater reactivity of catalytic amounts of $\mathrm{HI}$ relative to $\mathrm{HCl}$, reflects the lower $\mathrm{p} K_{\mathrm{a}}$ of $\mathrm{HI}{ }^{26}$ and relative ease of oxidation of iodine, ${ }^{27}$ which allows facile breakdown of $\mathrm{H}_{2} \mathrm{O}_{2} \cdot{ }^{24,25}$

Table 1. Yields Obtained from $\mathrm{H}_{2} \mathrm{O}_{2}$ and HI-Mediated Reactions. ${ }^{a}$ 


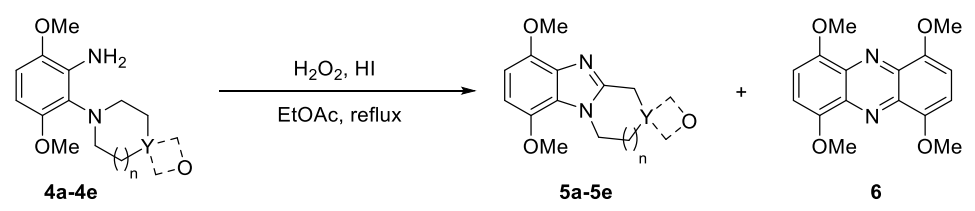

\begin{tabular}{|c|c|c|c|c|c|c|c|}
\hline Entry & Aniline & Y & $\mathrm{n}$ & $\mathrm{HI}(\mathrm{mmol})$ & Time (h) & Yield of $5 \mathbf{a}-5 \mathbf{e}(\%)^{b}$ & Yield of $6(\%)^{b, c}$ \\
\hline 1 & $4 a$ & 0 & 1 & 0.0 & 16 & $5 a, 0$ & 0 \\
\hline 2 & $4 a$ & 0 & 1 & 1.0 & 1 & $5 a, 56$ & 25 \\
\hline 3 & $4 a$ & 0 & 1 & 0.2 & 1 & $5 a, 69$ & 19 \\
\hline 4 & $4 b$ & & 1 & 0.2 & 1 & $\mathbf{5 b}, 74$ & 11 \\
\hline 5 & $4 c$ & $\mathrm{CH}_{2}$ & 1 & 0.2 & 1 & $\mathbf{5 c}, 72$ & 12 \\
\hline 6 & $4 d$ & $\mathrm{CH}_{2}$ & 0 & 0.2 & 1 & $5 d, 89$ & 0 \\
\hline 7 & $4 e$ & $\mathrm{CH}_{2}$ & 2 & 0.2 & 1 & $5 \mathbf{e}, 91$ & 0 \\
\hline 8 & $4 a$ & 0 & 1 & $0.2^{d}$ & 1 & $5 a, 28$ & 47 \\
\hline 9 & $4 a$ & 0 & 1 & $0.2^{d, e}$ & 16 & $\mathbf{5 a}, 4$ & 79 \\
\hline 10 & $4 a$ & 0 & 1 & $0.2^{d, f}$ & 24 & $5 a, 2$ & 82 \\
\hline
\end{tabular}

${ }^{a}$ Conditions: Aniline $(1.0 \mathrm{mmol}), \mathrm{H}_{2} \mathrm{O}_{2}(20.0 \mathrm{mmol})$, EtOAc $(40 \mathrm{~mL}) .{ }^{b I s o l a t e d . ~}{ }^{c}$ Precipitate. ${ }^{d}$ EtO Ac $(10 \mathrm{~mL}) .{ }^{e} 40^{\circ} \mathrm{C}$. frt.

\section{Scheme 3. Wohl-Aue Reaction. ${ }^{a}$}

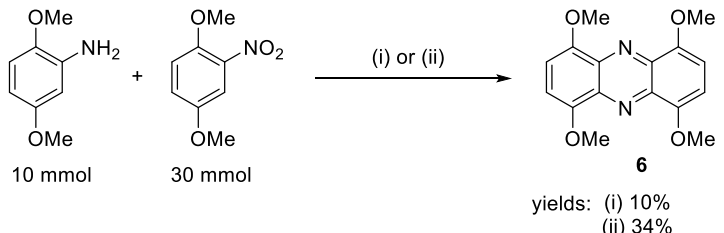

aConditions: (i) $\mathrm{KOH}(90 \mathrm{mmol})$, benzene $(50 \mathrm{~mL})$, reflux, $5 \mathrm{~h} .{ }^{22}$

(ii) $t$-BuOK $(40 \mathrm{mmol})$, toluene $(50 \mathrm{~mL})$, reflux, $16 \mathrm{~h}$.

Recently, chlorine (50 equiv) and bromine (50 equiv) with water (100 equiv) have been established as mediators for six-electron oxidation, converting 3,6-dimethoxy-2-(cycloamino)anilines into cyclized benzimidazolequinones (Scheme 1(b)). ${ }^{15}$ Molecular iodine is however, a less powerful oxidizing agent, ${ }^{27}$ and using the latter conditions did not give benzimidazolequinones, but mixtures of difficult to separate iodinated aromatics. In the iodine-mediated reactions, ethyl acetate was replaced by acetonitrile, since the former solvent is immiscible with water. Using iodine $(10$ equiv) in $20 \%$ aqueous acetonitrile, a 4 -electron oxidation occurred in 10 minutes to give cyclized non-iodinated benzimidazoles (Scheme 4(c)). Morpholine 4a and pyrrole 4d were converted to 6,9-dimethoxy[1,4] oxazino[4,3-a]benzimidazole (5a) and 5,8-dimethoxy pyrrolo[1,2-a]benzimidazole (5d) in $48 \%$ and $92 \%$ yield respectively. Similar to the $\mathrm{H}_{2} \mathrm{O}_{2}$ and $\mathrm{HI}$-mediated reaction, the five-membered cyclization was regioselective, and did not give phenazine, however the less favored morpholine cyclization gave sideproducts, including 6 in $6 \%$ yield. Presumably for iodine in water, the concentration of $\mathrm{HOI}$ is greater than in the $\mathrm{H}_{2} \mathrm{O}_{2}$ and HI-mediated reactions (in Table 1) resulting in intractable iodinated side-products.
Scheme 4. Alternative Oxidative Conditions and X-ray Crystal Structure with Cyclization of 4-Chloro-3,6-dimethoxy-2-(morpholin-4-yl)aniline (4f) (Thermal Ellipsoids Set at $40 \%$ Probability).
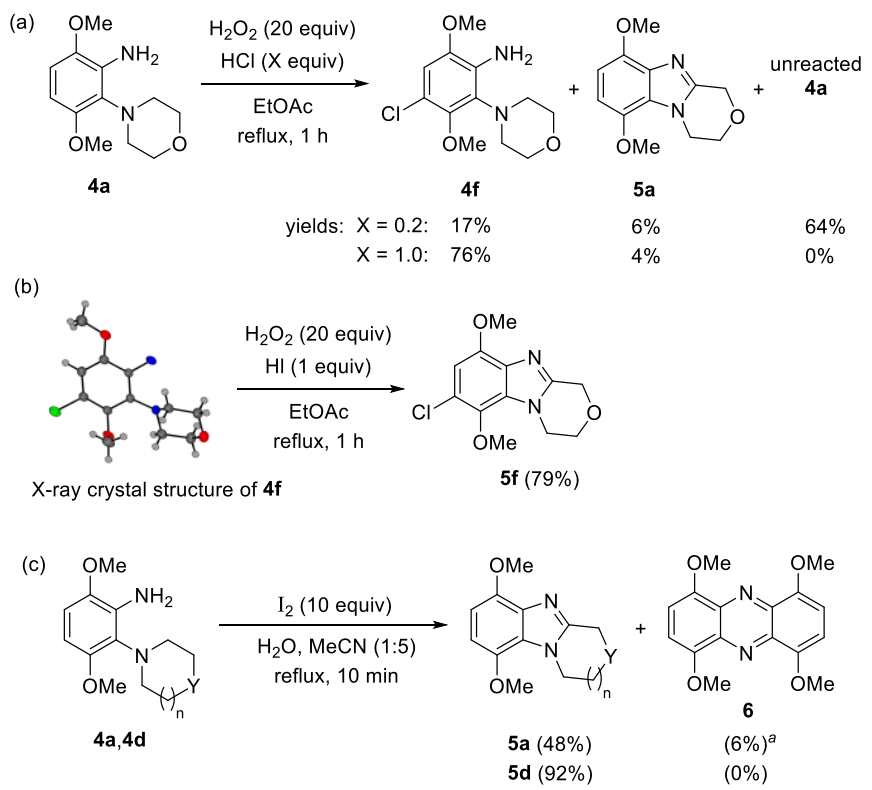

a\& an intractable mixture of iodinated benzimidazoles. 
Scheme 5. Proposed Mechanisms for the $\mathrm{H}_{2} \mathrm{O}_{2}$ and $\mathrm{HI}$ (Catalyst) Mediated Transformations Using 3,6-Dimethoxy-2(morpholin-4-yl)aniline (4a).

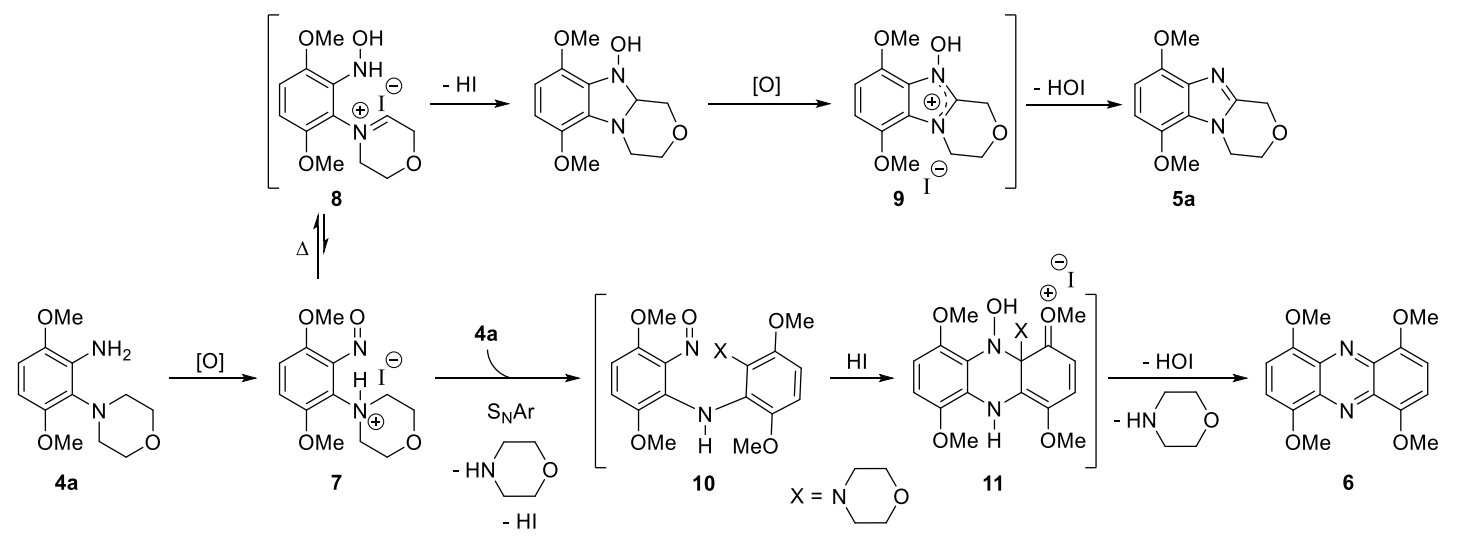

Common to the oxidative cyclization of $o$-cyclic amine substituted anilines to give benzimidazoles, ${ }^{10,28}$ and the WohlAue and other phenazine syntheses, ${ }^{19,20,29}$ is the likelihood of a nitroso-intermediate. Transformations via the $N$-oxide of the tert-amine of $\mathbf{4 a}$ are unlikely, with amine $\mathrm{N}$-oxides isolated intermediates only when the primary $\mathrm{NH}_{2}$ is deactivated to an acetamide. ${ }^{30,31}$ We were however unable to isolate a nitroso-intermediate, although encouragingly GC-MS of the reaction mixture (entry 10, Table 1) after 1 hour revealed an EI-MS fragmentation pattern supporting the formation of intermediate 7 (Figure S2, Scheme 5). The existence of highly reactive nitroso-intermediate $\mathbf{7}$ is supported by Meth-Cohn, who also refuted claims of isolations of $o$-nitroso-tert-anilines, including the nitrosation of $p$-benzyldimethylaniline, which gave only the nitro-compound. ${ }^{32} \mathrm{Ni}$ troso 7 should undergo a formal 1,5-hydride shift to the likely hydroxylamine 8,28,32-34 which subsequently cyclizes and is oxidized to give benzimidazole $\mathbf{5 a}$. The unexpected 1,4,6,9-tetramethoxyphenazine (6) formation via nitroso intermediate $\mathbf{7}$ would involve intermolecular reaction of $\mathbf{7}$ with starting aniline $\mathbf{4 a}$ resulting in nucleophilic aromatic substitution adduct $\mathbf{1 0}$. The proposed formation of iodide $\mathbf{1 1}$ is reminiscent of the Bamberger-Ham reaction for making phenazine- $N$-oxides, ${ }^{35}$ where two nitrosobenzenes substituted with para-electron-donating (through resonance) groups condense under acidic conditions. ${ }^{19,20}$ It is known that $\mathrm{HOI}$ reacts with $\mathrm{H}_{2} \mathrm{O}_{2}$ via a reduction to generate additional $\mathrm{HI},{ }^{24,25}$ which would favor conversion of $\mathbf{1 0}$ to 11. Further the yield of phenazine $\mathbf{6}$ is increased when using a full equival ent of HI (entry 2, Table 1). Similar to the conversion of hydroxylamine salts 9 and 11 into products $5 a$ and 6 respectively, Nguyen et al. al so proposed iodide as a directreductant for removal of oxygen in iodine-catalyzed reductive cyclizations of $o$-nitro-tert-anilines to give benzimidazoles. ${ }^{33}$ The necessity for the electron-donating (OMe) group in our $\mathrm{H}_{2} \mathrm{O}_{2}$ and $\mathrm{HI}$-mediated synthesis of phenazine was investigated using 2-(morpholin-4-yl)aniline (12a) ${ }^{13}$ and 2(2-oxa-7-azaspiro[3.5]nonan-7-yl)aniline (12b), prepared from 1-fluoro-2-nitrobenzene (Scheme 6). In both cases, oxidative cyclization adducts $\left(\mathbf{1 3}^{33}\right.$ and $\left.\mathbf{1 3 b}\right)$ were exclusively isolated in moderate yields (67 and 70\%) after column chromatography with phenazine $\mathbf{1 4}^{36}$ not observed. The presence of appropriately positioned OMe groups does not however guarantee phenazine formation. Surprisingly chloride 4f exclusively cyclized to give 7-chloro-6,9-dimethoxy-3,4-dihydro- $1 H$ - $[1,4]$ oxazino [4,3- $a$ ] benzimidazole (5f) in 79\% isolated yield (Scheme 4(b)), using the $\mathrm{H}_{2} \mathrm{O}_{2}$ and $\mathrm{HI}$ reaction conditions (in Table 1), which favored formation of 6 . Presumably electronic effects of the $\mathrm{Cl}$ substituent circumvent the $\mathrm{S}_{\mathrm{N}} \mathrm{Ar}$ step (in Scheme 5).

Scheme 6. Preparation of 2-(2-0xa-7-azaspiro[3.5]nonan-7yl)aniline (12b) and Oxidative Cyclizations.

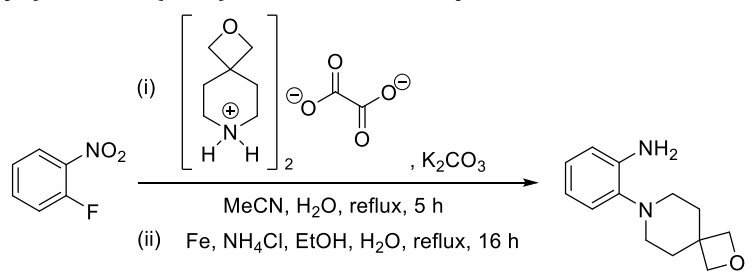

12b ( $83 \%$ for 2 steps)

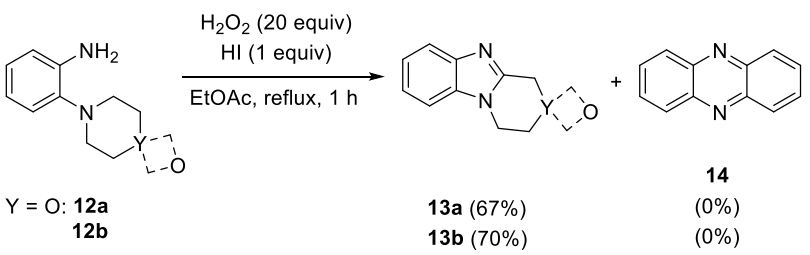

The structure of $6^{\prime}, 9^{\prime}$-dimethoxy-1',2'-dihydro- $4^{\prime} H$ spiro[oxetane-3,3'-pyrido[1,2-a]benzimidazole] (5b) was confirmed by X-ray crystallography prior to being subjected to oxidative demethylation (Scheme 7 and Figure S3). The hypervalentiodine reagent [bis(trifluoroacetoxy)iodo]benzene (PIFA) in water at room temperature is reported to convert $p$-dimethoxybenzenes to quinones. ${ }^{37}$ This mild procedure was used to give target ether-containing ring-fused benzimidazol equinones $\mathbf{1}$ and $\mathbf{2}$ in $74 \%$ and $78 \%$ yield from 6,9-dimethoxy-3,4-dihydro- $1 H$-[1,4] oxazino[4,3- $a]$ benzimidazole (5a) and spirocyclic oxetane ring-fused benzimidazole $(\mathbf{5 b})$ respectively. Importantly, PIFA unlike other oxidants, ${ }^{38,39}$ had no apparent adverse effect on the integrity of the oxetane motif.

In summary, $\mathrm{H}_{2} \mathrm{O}_{2}$ and $\mathrm{HI}$-mediated oxidative cyclization of 3,6-dimethoxy-2-(cycloamino)anilines to give the ringfused benzimidazoles can be tuned to alternatively give 1,4,6,9-tetramethoxyphenazine (6) in high yield. Phenazine formation is however not ubiquitous and competes with the 
six-membered cyclization only when the 3,6-dimethoxy-2(cycloamino)anilines are suitably activated. The detection of nitroso-intermediate 7 , has led to a proposed mechanism for this new HI-catalyzed reaction. Future work will establish the anti-tumor activity and NQ01 specificity of the synthesized benzimidazolequinones.

\section{Scheme 7. Oxidative Demethylation and X-ray Crystal Structure of 6',9'-Dimethoxy-1',2'-dihydro-4' $H$ - spiro[oxetane-3,3'-pyrido[1,2-a]benzimidazole] (5b) (Thermal Ellipsoids Set at $40 \%$ Probability).}

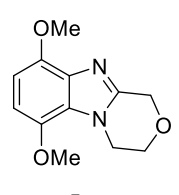

$5 a$

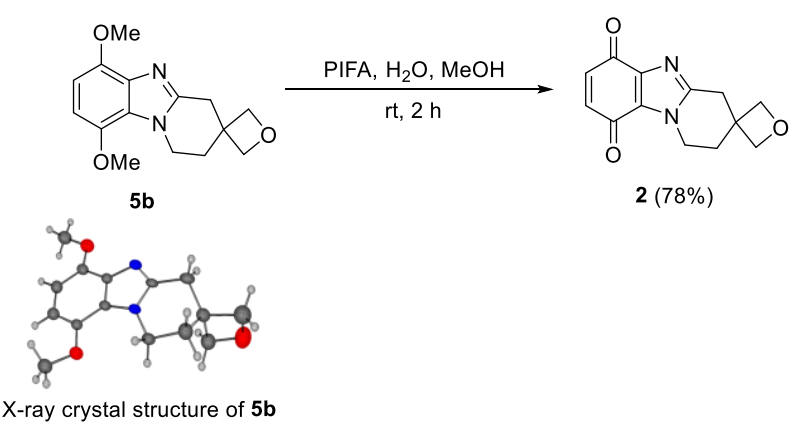

\section{Experimental Section}

\section{Materials}

All chemicals were obtained from commercial sources and used without further purification. 1,4-Dimethoxy-2,3-dinitrobenzene was prepared from 1,4-dimethoxybenzene (Sigma Aldrich, 99\% (GC)) and nitric acid (Honeywell Fluka, 64-66\%). ${ }^{40} \mathrm{Bis}$ (2-oxa-7-azaspiro[3.5]nonan-7-ium) ethanedioate was prepared using the procedure described by our group. ${ }^{17}$ The preparations of 3,6-dimethoxy-2-(morpholin4-yl)aniline (4a), 3,6-dimethoxy-2-(piperidin-1-yl)aniline (4c), 3,6-dimethoxy-2-(pyrrolidin-1-yl)aniline (4d) and 2(azepan-1-yl)-3,6-dimethoxyaniline (4e) were previously reported using the $S_{N} A r$ of morpholine (Alfa Aesar, 99\%), piperidine (Sigma Aldrich, 99\%), pyrrolidine (Acros, +99\%), and azepane (Fluorochem, $>98 \%$ ) respectively onto 1,4-dimethoxy-2,3-dinitrobenzene, followed by reduction with iron powder (Alfa Aesar, reduced, 99\%).14,15 2,5-Dimethoxyaniline was prepared by the reduction of 1,4-dimethoxy-2-nitrobenzene (TCI, >99.0\% (GC)) using iron powder. ${ }^{41} 2$-(Morpholin-4-yl)aniline (12a) ${ }^{13}$ was prepared by the $S_{\mathrm{N}} \mathrm{Ar}$ of morpholine onto 1-fluoro-2-nitrobenzene (Fluorochem, 99\%), followed by reduction with iron powder. $\mathrm{H}_{2} \mathrm{O}_{2}$ (Honeywell Fluka, 50\% w/v in water, stabilized), HI (Sigma Aldrich, 57\% w/v in water), HCl (Sigma Aldrich, $37 \% \mathrm{w} / \mathrm{v}$ in water), $\mathrm{I}_{2}$ (VWR, $\geq 99 \%$, resublimed), and PIFA (Sigma Aldrich, 97\%) were used as received. Thin layer chromatography (TLC) was performed on TLC silica gel 60
$\mathrm{F}_{254}$ plates. Flash column chromatography was carried out on silica gel (Apollo Scientific 60/40-63 $\mu \mathrm{m}$ ).

Measurements

Melting points: Melting points were measured on a Stuart Scientific melting point apparatus SMP1, except for 1,4,6,9tetramethoxyphenazine (6) recorded using differential scanning cal orimetry (DSC) performed on a Mettler Toledo DSC822 differential scanning calorimeter, using standard aluminum pans.

Gas chromatography: GC-MS used to detect the formation of nitrosoarene 7 was performed on an Agilent 6890N Series GC system equipped with an Agilent 5973 Inert Mass Selective Detector (EI) and an SGE, $25 \mathrm{~m}$, ID $0.25 \mathrm{~mm}$, FD $0.25 \mu \mathrm{m}$ column. The carrier gas used was $\mathrm{He}$ at a flow rate of $1.3 \mathrm{~mL} / \mathrm{min}$. The injector heated to $80{ }^{\circ} \mathrm{C}$ and the oven temperature increased from 80 to $280^{\circ} \mathrm{C}$ at the rate of 10 ${ }^{\circ} \mathrm{C} / \mathrm{min}$ and increased to $320^{\circ} \mathrm{C}$ at $40^{\circ} \mathrm{C} / \mathrm{min}$.

Infrared (IR) spectroscopy: IR spectra were recorded using a Perkin-Elmer Spec 1 with ATR attached.

Nuclear Magnetic Resonance (NMR) spectroscopy: NMR spectra for compounds $\mathbf{2}, \mathbf{3}, \mathbf{4 b}$ and $\mathbf{5 b}$ were recorded using a Jeol ECX $400 \mathrm{MHz}$ instrument equipped with a DEC AXP 300 computer workstation. NMR Spectra for all other compounds were recorded using a Bruker Avance II $400 \mathrm{MHz}$ spectrometer. The chemical shifts are in ppm relative to tetramethylsilane. ${ }^{13} \mathrm{C}-\mathrm{NMR}$ spectra at $100 \mathrm{MHz}$ are with complete proton decoupling. NMR assignments are supported by Distortionless Enhancement by Polarization Transfer (DEPT) and ${ }^{1} \mathrm{H}^{-1} \mathrm{H}$ and ${ }^{1} \mathrm{H}-{ }^{-13} \mathrm{C}$ correlation.

High resolution mass spectrometry (HRMS): HRMS spectra were obtained using ESI time-of-flight mass spectrometer (TOFMS) on a Waters LCT Mass Spectrometry instrument. The precision of all accurate mass measurements was better than $5 \mathrm{ppm}$.

$\mathrm{X}$-ray crystallography: A single crystal of $\mathbf{4 f}$ was grown from $\mathrm{CH}_{2} \mathrm{Cl}_{2}$ at $2{ }^{\circ} \mathrm{C}$, and a single crystal of $\mathbf{5} \mathbf{b}$ was grown by slow evaporation from $\mathrm{CH}_{2} \mathrm{Cl}_{2}$. Single crystal data was collected using an Oxford Diffraction Xcalibur system operated using the CrysAlisPro software and the data collection temperature was controlled at $298 \mathrm{~K}$ using a Cryojet system from Rigaku Oxford Diffraction. The crystal structures were solved using ShelxT version 2014/55,42 and refined using ShelxL version $2017 / 1,43$ both of which were operated within the Oscail software package. ${ }^{44}$ Crystall ographic data for compounds $\mathbf{4 f}$ and $\mathbf{5 b}$ was deposited with the Cambridge Crystallographic Data Centre with depositnumber of CCDC 1917886 and CCDC 1917885 respectively. This data is available free of charge via www.ccdc.cam.ac.uk/data_request/cif (or from the Cambridge Crystallographic Data Centre, 12 Union Road, Cambridge CB2 1EZ, U.K.; fax +44 1223 336033; or e-mail deposit@ccdc.cam.ac.uk).

Experimental Procedures

Synthesis of 3,6-Dimethoxy-2-(2-oxa-7-azaspiro[3.5]nonan7-yl)aniline (4b). 1,4-Dimethoxy-2,3-dinitrobenzene (0.680 g, $2.98 \mathrm{mmol})$, bis(2-oxa-7-azaspiro[3.5]nonan-7-ium) ethanedioate $(2.053 \mathrm{~g}, 5.96 \mathrm{mmol})$ and $\mathrm{K}_{2} \mathrm{CO}_{3}(1.647 \mathrm{~g}$, $11.92 \mathrm{mmol})$ in $\mathrm{MeCN}(30 \mathrm{~mL})$ and $\mathrm{H}_{2} \mathrm{O}(6 \mathrm{~mL})$ were heated at reflux for $40 \mathrm{~h}$. The mixture was evaporated, dissolved in EtOAc ( $30 \mathrm{~mL})$ and washed with brine $(3 \times 20 \mathrm{~mL})$. The organic extract was dried $\left(\mathrm{MgSO}_{4}\right)$, evaporated, and purified 
by column chromatography using gradient elution of petroleum ether/EtOAc to give 7-(3,6-dimethoxy-2-nitrophenyl)2-oxa-7-azaspiro[3.5]nonane (3) (0.624 g, 68\%) as a yellow solid; $R_{\mathrm{f}} 0.44$ (1:1 pet. ether/EtOAc); m.p. $125-127^{\circ} \mathrm{C}$; $v_{\max }$ (neat, $\mathrm{cm}^{-1}$ ) 2931, 2861, 2841, $1539\left(\mathrm{NO}_{2}\right), 1495,1381$ $\left(\mathrm{NO}_{2}\right), 1256,1094,1057 ;{ }^{1} \mathrm{H} \mathrm{NMR}\left(400 \mathrm{MHz}, \mathrm{CDCl}_{3}\right) \delta: 6.83$ $(\mathrm{d}, J=9.2 \mathrm{~Hz}, 1 \mathrm{H}), 6.74(\mathrm{~d}, J=9.2 \mathrm{~Hz}, 1 \mathrm{H}), 4.42\left(\mathrm{~s}, 4 \mathrm{H}, \mathrm{OCH}_{2}\right)$, 3.80 (s, 3H, Me), 3.78 (s, 3H, Me), 2.97-2.90 (br.s, 4H), 1.881.80 (br.s, $4 \mathrm{H}) ;{ }^{13} \mathrm{C}\left\{{ }^{1} \mathrm{H}\right\}$ NMR $\left(100 \mathrm{MHz}^{\mathrm{CDCl}}{ }_{3}\right) \delta: 152.7$, 144.5, 141.9, 133.9 (all C), 112.9, 109.4 (both CH), 82.1 $\left(\mathrm{OCH}_{2}\right), 56.8,56.2$ (both $\left.\mathrm{Me}\right), 47.8\left(\mathrm{CH}_{2}\right), 38.4(\mathrm{C}), 35.6$ $\left(\mathrm{CH}_{2}\right)$; HRMS (ESI) $m / z[\mathrm{M}+\mathrm{H}]^{+}$Calcd for $\mathrm{C}_{15} \mathrm{H}_{21} \mathrm{~N}_{2} \mathrm{O}_{5}$ 309.1449; Found 309.1450.

Nitrobenzene $3(0.616 \mathrm{~g}, 2.00 \mathrm{mmol})$, iron powder $(0.357 \mathrm{~g}$, $6.40 \mathrm{mmol}$ ) and $\mathrm{NH}_{4} \mathrm{Cl}(55 \mathrm{mg}, 1.00 \mathrm{mmol})$ in EtOH ( $\left.40 \mathrm{~mL}\right)$ and $\mathrm{H}_{2} \mathrm{O}(12 \mathrm{~mL})$ were heated at reflux for $18 \mathrm{~h}$. The mixture was filtered through Celite ${ }^{\circledR}$, evaporated, dissolved in EtOAc $(80 \mathrm{~mL})$ and washed with brine $(2 \times 60 \mathrm{~mL})$. The organic extract was dried $\left(\mathrm{MgSO}_{4}\right)$, evaporated, and purified by column chromatography using gradient elution of petroleum ether/EtOAc to give $\mathbf{4 b}(0.445 \mathrm{~g}, 80 \%)$ as an off-white solid; $R_{\mathrm{f}} 0.33$ (3:1 pet. ether/ EtOAc); m.p. $138-140{ }^{\circ} \mathrm{C} ; \nu_{\max }$ (neat, $\mathrm{cm}^{-1}$ ) 3444, 3338, 2989, 2917, 2856, 2830, 1605, 1556, 1490, 1258, 1107; ${ }^{1} \mathrm{H}$ NMR (400 MHz, $\left.\mathrm{CDCl}_{3}\right) \delta: 6.54(\mathrm{~d}, J=$ $8.8 \mathrm{~Hz}, 1 \mathrm{H}), 6.13(\mathrm{~d}, J=8.8 \mathrm{~Hz}, 1 \mathrm{H}), 4.56\left(\mathrm{~s}, 2 \mathrm{H}, \mathrm{OCH}_{2}\right), 4.40$ (s, $2 \mathrm{H}, \mathrm{OCH}_{2}$ ), 4.37-4.27 (br.s, disappears with $\mathrm{D}_{2} \mathrm{O}, 2 \mathrm{H}$, $\mathrm{NH}_{2}$ ), 3.78 (s, 3H, Me), 3.71 (s, 3H, Me), 3.14 (t, $J=12.1 \mathrm{~Hz}$, 2H), $2.75(\mathrm{~d}, J=11.4 \mathrm{~Hz}, 2 \mathrm{H}), 2.13(\mathrm{~d}, J=12.4 \mathrm{~Hz}, 2 \mathrm{H}), 1.79$ $1.66(\mathrm{~m}, 2 \mathrm{H}) ;{ }^{13} \mathrm{C}\left\{{ }^{1} \mathrm{H}\right\} \mathrm{NMR}\left(100 \mathrm{MHz}, \mathrm{CDCl}_{3}\right) \delta: 153.6,142.1$, 135.4, 126.3 (all C), 107.5, 99.0 (both $\mathrm{CH}$ ), 82.8, 81.7 (both $\mathrm{OCH}_{2}$ ), 56.1, 55.5 (both Me), $47.3\left(\mathrm{CH}_{2}\right), 38.6(\mathrm{C}), 36.7\left(\mathrm{CH}_{2}\right)$; HRMS (ESI) $m / z[\mathrm{M}+\mathrm{H}]+$ Calcd for $\mathrm{C}_{15} \mathrm{H}_{23} \mathrm{~N}_{2} \mathrm{O}_{3}$ 279.1709; Found 279.1701.

Synthesis of 2-(2-oxa-7-azaspiro[3.5]nonan-7-yl)aniline (12b). 1-Fluoro-2-nitrobenzene (0.296 g, $2.10 \mathrm{mmol}$ ), bis (2oxa-7-azaspiro[3.5] nonan-7-ium) ethanedioate $(0.722 \mathrm{~g}$, $2.10 \mathrm{mmol}$ ) and $\mathrm{K}_{2} \mathrm{CO}_{3}(1.161 \mathrm{~g}, 8.40 \mathrm{mmol})$ in MeCN (20 $\mathrm{mL}$ ) and $\mathrm{H}_{2} \mathrm{O}(4 \mathrm{~mL})$ were heated at reflux for $5 \mathrm{~h}$. The mixture was evaporated, dissolved in EtOAc $(20 \mathrm{~mL})$ and washed with brine (3 $\times 20 \mathrm{~mL})$. The organic extract was dried $\left(\mathrm{MgSO}_{4}\right)$, evaporated, and purified by column chromatography using gradient elution of petroleum ether/EtOAc to give 7-(2-nitrophenyl)-2-oxa-7-azaspiro[3.5]nonane $(0.489 \mathrm{~g}, 94 \%)$ as an orange solid; $R_{\mathrm{f}} 0.38$ (3:2 pet. ether/EtOAc); m.p. $95-96^{\circ} \mathrm{C}$; $v_{\max }$ (neat, $\mathrm{cm}^{-1}$ ) 2931, 2859, 2814, 1603, 1567, $1519\left(\mathrm{NO}_{2}\right), 1488,1463,1444,1384$, $1343\left(\mathrm{NO}_{2}\right), 1298,1234,1167,1129 ;{ }^{1} \mathrm{H}$ NMR $(400 \mathrm{MHz}$, $\left.\mathrm{CDCl}_{3}\right) \delta: 7.76(\mathrm{dd}, J=8.1,1.6 \mathrm{~Hz}, 1 \mathrm{H}), 7.48-7.43(\mathrm{~m}, 1 \mathrm{H})$, $7.11(\mathrm{dd}, J=8.3,1.1 \mathrm{~Hz}, 1 \mathrm{H}), 7.05-7.00(\mathrm{~m}, 1 \mathrm{H}), 4.48(\mathrm{~s}, 4 \mathrm{H}$, $\left.\mathrm{OCH}_{2}\right), 2.95(\mathrm{t}, J=5.5 \mathrm{~Hz}, 4 \mathrm{H}), 2.02(\mathrm{t}, J=5.5 \mathrm{~Hz}, 4 \mathrm{H}) ;{ }^{13} \mathrm{C}\left\{{ }^{1} \mathrm{H}\right\}$ NMR (100 MHz, $\left.\mathrm{CDCl}_{3}\right) \delta: 146.3,143.3$ (both C), 133.4, $125.9,121.7,121.2$ (all $\mathrm{CH}), 81.6\left(\mathrm{OCH}_{2}\right), 49.2\left(\mathrm{CH}_{2}\right), 38.3$ (C), $34.9\left(\mathrm{CH}_{2}\right)$; HRMS (ESI) $\mathrm{m} / z[\mathrm{M}+\mathrm{H}]^{+}$Calcd for $\mathrm{C}_{13} \mathrm{H}_{17} \mathrm{~N}_{2} \mathrm{O}_{3}$ 249.1239; Found 249.1245.

The above nitrobenzene $(0.480 \mathrm{~g}, 1.94 \mathrm{mmol})$, iron powder $(0.347 \mathrm{~g}, 6.21 \mathrm{mmol})$ and $\mathrm{NH}_{4} \mathrm{Cl}(52 \mathrm{mg}, 0.97 \mathrm{mmol})$ in $\mathrm{EtOH}$ $(30 \mathrm{~mL})$ and $\mathrm{H}_{2} \mathrm{O}(10 \mathrm{~mL})$ were heated at reflux for $16 \mathrm{~h}$. The mixture was filtered through Celite ${ }^{\circledR}$, evaporated, dissolved in EtOAc $(60 \mathrm{~mL})$ and washed with brine $(2 \times 40 \mathrm{~mL})$. The organic extract was dried $\left(\mathrm{MgSO}_{4}\right)$, evaporated, and purified by column chromatography using gradientelution of petroleum ether/EtOAc to give $\mathbf{1 2 b}(0.372 \mathrm{~g}, 88 \%)$ as a pale brown solid; $R_{\mathrm{f}} 0.35$ (3:2 pet. ether/ EtOAc); m.p. 137-139 ${ }^{\circ} \mathrm{C}$; $v_{\max }\left(\right.$ neat, $\mathrm{cm}^{-1}$ ) 3408, 3325, 3032, 2914, 2856, 2806, 2740, 2677, 1617, 1501, 1461, 1438, 1425, 1383, 1289, $1211,1135,1125 ;{ }^{1} \mathrm{H}$ NMR $\left(400 \mathrm{MHz}, \mathrm{CDCl}_{3}\right) \delta:$ 6.94-6.86 (m, 2H), 6.74-6.65 (m, 2H), $4.46\left(\mathrm{~s}, 4 \mathrm{H}, \mathrm{OCH}_{2}\right), 4.02-3.87$ (br.s, disappears with $\mathrm{D}_{2} \mathrm{O}, 2 \mathrm{H}, \mathrm{NH}_{2}$ ), 2.89-2.60 (br.s, $4 \mathrm{H}$ ), 2.06-1.86 (br.s, $4 \mathrm{H}) ;{ }^{13} \mathrm{C}\left\{{ }^{1} \mathrm{H}\right\} \mathrm{NMR}\left(100 \mathrm{MHz}, \mathrm{CDCl}_{3}\right) \delta: 141.6$, 139.6 (both C), 124.6, 119.8, 118.5, 115.1 (all CH), 81.9 $\left(\mathrm{OCH}_{2}\right), 48.7\left(\mathrm{CH}_{2}\right), 38.6(\mathrm{C}), 35.9\left(\mathrm{CH}_{2}\right) ; \mathrm{HRMS}(\mathrm{ESI}) \mathrm{m} / z[\mathrm{M}$ $+\mathrm{H}]+$ Calcd for $\mathrm{C}_{13} \mathrm{H}_{19} \mathrm{~N}_{2} \mathrm{O}$ 219.1497; Found 219.1487.

\section{$\mathrm{H}_{2} \mathrm{O}_{2}$ and $\mathrm{HX}$-Mediated Transformations}

Reaction conditions are given in Table 1 and Schemes 4(b), and 6 for $\mathrm{H}_{2} \mathrm{O}_{2}$ and $\mathrm{HI}$, and in Scheme 4(a) for $\mathrm{H}_{2} \mathrm{O}_{2}$ and $\mathrm{HCl}$. $\mathrm{H}_{2} \mathrm{O}_{2}$ and $\mathrm{HX}$ were sequentially added dropwise to a stirred solution of the anilines ( $1 \mathrm{mmol})$ in EtOAc $(10$ or $40 \mathrm{~mL})$ at the indicated reaction temperatures. For the room temperature reaction of aniline $4 \mathbf{a}$, the addition of $\mathrm{H}_{2} \mathrm{O}_{2}$ and $\mathrm{HI}$ were done over ice, and the mixture was then allowed to warm to room temperature. At the end of the reaction, the solution was filtered, and the orange precipitate washed with EtOAc ( $30 \mathrm{~mL})$ to give 1,4,6,9-tetramethoxyphenazine (6). The filtrate was washed with $\mathrm{Na}_{2} \mathrm{CO}_{3}$ (satd., $60 \mathrm{~mL}$ ), and dried $\left(\mathrm{MgSO}_{4}\right)$. The organic extract was evaporated, and the residue triturated from $\mathrm{Et}_{2} \mathrm{O}$ to give benzimidazoles $\mathbf{5 a - 5 d}$. Azepane 5e did not require purification. The residues of $\mathbf{4 f}$, 5f, 13a and 13b were purified by column chromatography using gradient elution of petroleum ether/EtOAc.

6,9-Dimethoxy-3,4-dihydro-1H-[1,4]oxazino[4,3-a]benzimidazole (5a) (0.161 g, 69\%, Table 1, entry 3); pale brown solid; m.p. 109-111 ${ }^{\circ} \mathrm{C}$; $v_{\max }$ (neat, $\mathrm{cm}^{-1}$ ) 2929, 2827, 1523, 1475, $1440,1426,1402,1316,1259,1227,1193,1165,1119$, 1103, 1084; ${ }^{1} \mathrm{H}$ NMR (400 MHz, $\left.\mathrm{CDCl}_{3}\right) \delta: 6.45\left(\mathrm{AB}_{\mathrm{q}}, J=8.6\right.$ $\mathrm{Hz}, 2 \mathrm{H}), 4.92\left(\mathrm{~s}, 2 \mathrm{H}, 1-\mathrm{CH}_{2}\right), 4.41(\mathrm{t}, J=5.2 \mathrm{~Hz}, 2 \mathrm{H}), 4.03(\mathrm{t}, J$ $=5.2 \mathrm{~Hz}, 2 \mathrm{H}), 3.87(\mathrm{~s}, 3 \mathrm{H}, \mathrm{Me}), 3.79(\mathrm{~s}, 3 \mathrm{H}, \mathrm{Me}) ;{ }^{13} \mathrm{C}\left\{{ }^{1} \mathrm{H}\right\} \mathrm{NMR}$ $\left(100 \mathrm{MHz} \mathrm{CDCl}_{3}\right) \delta: 146.3,145.8,141.8,134.4,125.0$ (all C), 102.8, 102.0 (both $\mathrm{CH}), 65.5\left(1-\mathrm{CH}_{2}\right), 64.3\left(\mathrm{CH}_{2}\right), 55.9,55.8$ (both Me), $44.9\left(\mathrm{CH}_{2}\right)$; HRMS (ESI) $m / z[\mathrm{M}+\mathrm{H}]+$ Calcd for $\mathrm{C}_{12} \mathrm{H}_{15} \mathrm{~N}_{2} \mathrm{O}_{3}$ 235.1083; Found 235.1081, and 1,4,6,9-tetramethoxyphenazine (6) (29 mg, 19\%); orange solid; m.p. (DSC) onset $351.2^{\circ} \mathrm{C}$, peak max $355.9^{\circ} \mathrm{C}$ (litm.p. ${ }^{26}>360{ }^{\circ} \mathrm{C}$ ); $\nu_{\max }\left(\right.$ neat, $\left.\mathrm{cm}^{-1}\right) 3075,3010,2900,2833,1177,1622,1492$, $1456,1445,1437,1322,1266,1248,1197,1157,1127$, 1109; ${ }^{1} \mathrm{H} \mathrm{NMR}\left(400 \mathrm{MHz}, \mathrm{CDCl}_{3}\right) \delta: 6.97(\mathrm{~s}, 4 \mathrm{H}), 4.09(\mathrm{~s}, 12 \mathrm{H}$, $\mathrm{Me}) ;{ }^{13} \mathrm{C}\left\{{ }^{1} \mathrm{H}\right\} \mathrm{NMR}\left(100 \mathrm{MHz}, \mathrm{CDCl}_{3}\right) \delta: 148.8,135.6$ (both $\mathrm{C}$ ), $106.0(\mathrm{CH}), 56.1$ (Me); HRMS (ESI) $m / z[\mathrm{M}+\mathrm{H}]+$ Calcd for $\mathrm{C}_{16} \mathrm{H}_{17} \mathrm{~N}_{2} \mathrm{O}_{4}$ 301.1188; Found 301.1179.

6',9'-Dimethoxy-1',2'-dihydro-4'H-spiro[oxetane-3,3'-pyrido[1,2-a]benzimidazole] (5b) (0.203 g, 74\%); off-white solid; m.p. $166-167^{\circ} \mathrm{C}$; $v_{\max }\left(\right.$ neat, $\mathrm{cm}^{-1}$ ) 3004, 2931, 2865, 2837, $1810,1606,1523,1441,1260,1223,1100,1082 ;{ }^{1} \mathrm{H}$ NMR $\left(400 \mathrm{MHz} \mathrm{CDCl}_{3}\right) \delta: 6.47(\mathrm{~s}, 2 \mathrm{H}), 4.53\left(\mathrm{AB}_{\mathrm{q}}, J=6.1 \mathrm{~Hz}, 4 \mathrm{H}\right.$, $\left.\mathrm{OCH}_{2}\right), 4.45\left(\mathrm{t}, J=6.3 \mathrm{~Hz}, 2 \mathrm{H}, 1^{\prime}-\mathrm{CH}_{2}\right), 3.92(\mathrm{~s}, 3 \mathrm{H}, \mathrm{Me}), 3.83$ (s, 3H, Me), 3.32 (s, 2H, 4' $\left.-\mathrm{CH}_{2}\right), 2.34\left(\mathrm{t}, J=6.3 \mathrm{~Hz}, 2 \mathrm{H}, 2^{\prime}-\right.$ $\left.\mathrm{CH}_{2}\right) ;{ }^{13} \mathrm{C}\left\{{ }^{1} \mathrm{H}\right\}$ NMR $\left(100 \mathrm{MHz}, \mathrm{CDCl}_{3}\right) \delta: 148.2,145.6,141.8$, 135.0, 125.3 (all C), 102.6, 101.8 (both $\mathrm{CH}), 80.8\left(\mathrm{OCH}_{2}\right)$, 55.93, 55.89 (both Me), $41.7\left(1^{\prime}-\mathrm{CH}_{2}\right), 37.7$ (C), 35.0 (4'$\mathrm{CH}_{2}$ ), $31.3\left(2^{\prime}-\mathrm{CH}_{2}\right)$; HRMS (ESI) $m / z[\mathrm{M}+\mathrm{H}]^{+}$Calcd for $\mathrm{C}_{15} \mathrm{H}_{19} \mathrm{~N}_{2} \mathrm{O}_{3}$ 275.1396; Found 275.1380, and 1,4,6,9-tetramethoxyphenazine (6) (17 mg, 11\%). 
6,9-Dimethoxy-1,2,3,4-tetrahydropyrido[1,2-a]benzimidazole (5c) $(0.167 \mathrm{~g}$, $72 \%)$; brown solid; spectral data and melting point consistent with the literature, ${ }^{14}$ and 1,4,6,9-tetramethoxyphenazine (6) (18 mg, 12\%).

5,8-Dimethoxy-2,3-dihydro-1H-pyrrolo[1,2-a]benzimidazole (5d) (0.194 g, 89\%); off-white solid; spectral data and melting point consistent with the literature. ${ }^{14}$

1,4-Dimethoxy-7,8,9,10-tetrahydro-6H-azepino[1,2-a]benzimidazole (5e) (0.224 g, 91\%); brown oil; spectral data consistent with the literature. ${ }^{14}$

4-Chloro-3,6-dimethoxy-2-(morpholin-4-yl)aniline

$(0.207 \mathrm{~g}, 76 \%) ; R_{\mathrm{f}} 0.51$ (1:1 pet. ether/EtOAc); pale brown solid; m.p. $149-151^{\circ} \mathrm{C}$; $v_{\max }$ (neat, $\mathrm{cm}^{-1}$ ) 3434, 3335, 2960, 2909, 2881, 2843, 1596, 1549, 1480, 1456, 1445, 1419, $1261,1177,1153,1041 ;{ }^{1} \mathrm{H}$ NMR $\left(400 \mathrm{MHz}, \mathrm{CDCl}_{3}\right) \delta: 6.65$ (s, 1H), 3.98-3.88 (br.s, 2H), 3.87 (s, 3H, Me), 3.81 (s, 3H, Me), 3.78-3.63 (br.s, 2H), 3.52-3.35 (br.s, 2H), 2.87-2.68 (br.s, $2 \mathrm{H}), \mathrm{NH}_{2}$ is absent; ${ }^{13} \mathrm{C}\left\{{ }^{1} \mathrm{H}\right\} \mathrm{NMR}\left(100 \mathrm{MHz}, \mathrm{CDCl}_{3}\right) \delta$ : 148.9, 143.6, 133.7, 130.5, 114.8 (all C), 109.3 (CH), 68.4 (2 $\mathrm{xCH}_{2}$ ), 61.8, 56.0, (both Me), $51.0\left(2 \mathrm{x} \mathrm{CH}_{2}\right.$ ); HRMS (ESI) $\mathrm{m} / \mathrm{z}$ $[\mathrm{M}+\mathrm{H}]+$ Calcd for $\mathrm{C}_{12} \mathrm{H}_{18} \mathrm{~N}_{2} \mathrm{O}_{3} \mathrm{Cl}$ 273.1006; Found 273.1012; and 6,9-dimethoxy-3,4-dihydro-1H-[1,4]oxazino[4,3-a]benzimidazole (5a) (9 mg, 4\%); $R_{\mathrm{f}} 0.35$ (EtOAc).

7-Chloro-6,9-dimethoxy-3,4-dihydro-1H-[1,4]oxazino[4,3a]benzimidazole (5f) (0.212 g, 79\%); $R_{\mathrm{f}} 0.43$ (EtOAc); brown solid; m.p. $144-146^{\circ} \mathrm{C}$; $v_{\max }$ (neat, $\mathrm{cm}^{-1}$ ) 2931, 2836, 2359, $1605,1508,1473,1428,1399,1309,1212,1153,1111$, $1070 ;{ }^{1} \mathrm{H} \mathrm{NMR}\left(400 \mathrm{MHz}, \mathrm{CDCl}_{3}\right) \delta: 6.64(\mathrm{~s}, 1 \mathrm{H}), 5.00(\mathrm{~s}, 2 \mathrm{H}$, $\left.1-\mathrm{CH}_{2}\right), 4.44(\mathrm{t}, J=5.2 \mathrm{~Hz}, 2 \mathrm{H}), 4.17(\mathrm{t}, J=5.2 \mathrm{~Hz}, 2 \mathrm{H}), 3.96$ $(\mathrm{s}, 3 \mathrm{H}, \mathrm{Me}), 3.94(\mathrm{~s}, 3 \mathrm{H}, \mathrm{Me}) ;{ }^{13} \mathrm{C}\left\{{ }^{1} \mathrm{H}\right\}$ NMR $\left(100 \mathrm{MHz}, \mathrm{CDCl}_{3}\right)$ $\delta: 147.7,147.0,136.7,133.4,128.5,120.5$ (all C), $104.8(\mathrm{CH})$, 65.5, $64.1\left(\mathrm{CH}_{2}\right), 62.5,56.1$ (both Me), $44.2\left(\mathrm{CH}_{2}\right)$; HRMS (ESI) $\mathrm{m} / \mathrm{z}:[\mathrm{M}+\mathrm{H}]+$ Calcd for $\mathrm{C}_{12} \mathrm{H}_{14} \mathrm{~N}_{2} \mathrm{O}_{3} \mathrm{Cl}$ 269.0693; Found 269.0685 .

3,4-Dihydro-1H-[1,4]oxazino[4,3-a]benzimidazole (13a) ( 0.117 g, 67\%); pale brown solid; $R_{\mathrm{f}} 0.21$ (EtOAc); spectral data and melting point consistent with the literature. ${ }^{33}$

1',2'-dihydro-4'H-spiro[oxetane-3,3'-pyrido[1,2-a]benzimidazole] (13b) (0.149 g, 70\%); off-white solid; $R_{\mathrm{f}} 0.23$ (1:10 $\mathrm{MeOH} / \mathrm{EtOAc}$ ) m.p. $141-143{ }^{\circ} \mathrm{C} ; v_{\max }$ (neat, $\mathrm{cm}^{-1}$ ) 3052 , 2936, 2864, 1668, 1616, 1516, 1485, 1457, 1417, 1371, $1344,1319,1283,1228,1161 ;{ }^{1} \mathrm{H}$ NMR $\left(400 \mathrm{MHz}, \mathrm{CDCl}_{3}\right) \delta$ : 7.73-7.67 (m, $1 \mathrm{H}), 7.33-7.28(\mathrm{~m}, 1 \mathrm{H}), 7.28-7.22(\mathrm{~m}, 2 \mathrm{H})$, $4.59\left(\mathrm{AB}_{\mathrm{q}}, J=6.2 \mathrm{~Hz}, 4 \mathrm{H}, \mathrm{OCH}_{2}\right), 4.14\left(\mathrm{t}, J=6.3 \mathrm{~Hz}, 2 \mathrm{H}, 1^{\prime}\right.$ $\left.\mathrm{CH}_{2}\right), 3.40\left(\mathrm{~s}, 2 \mathrm{H}, 4^{\prime}-\mathrm{CH}_{2}\right), 2.47\left(\mathrm{t}, J=6.3 \mathrm{~Hz}, 2 \mathrm{H}, 2^{\prime}-\mathrm{CH}_{2}\right.$ ); ${ }^{13} \mathrm{C}\left\{{ }^{1} \mathrm{H}\right\}$ NMR $\left(100 \mathrm{MHz}, \mathrm{CDCl}_{3}\right) \delta: 149.5,143.2,134.3$ (all C), $122.4,122.2,119.2,108.9$ (all $\mathrm{CH}), 80.6\left(\mathrm{OCH}_{2}\right), 38.8\left(1^{\prime}-\right.$ $\mathrm{CH}_{2}$ ), 38.0 (C), $34.9\left(4^{\prime}-\mathrm{CH}_{2}\right), 30.7\left(2^{\prime}-\mathrm{CH}_{2}\right)$; HRMS (ESI) $\mathrm{m} / \mathrm{z}$ $[\mathrm{M}+\mathrm{H}]+{ }^{+} \mathrm{C}_{13} \mathrm{H}_{15} \mathrm{~N}_{2} \mathrm{O}$ Calcd for 215.1184; Found 215.1180.

Modified Wohl-Aue Reaction

Reaction conditions are given in Scheme 3. At the end of the reaction, the mixture was filtered, and the precipitate washed with water $(30 \mathrm{~mL})$ to give $6(1.02 \mathrm{~g}, 34 \%)$ as an orange solid. Spectral data and melting point of phenazine 6 is consistent with the above.

Aqueous $\mathrm{I}_{2}$-mediated transformations

Anilines ( $1.00 \mathrm{mmol})$ in $\mathrm{MeCN}(10 \mathrm{~mL})$ and $\mathrm{H}_{2} \mathrm{O}(2 \mathrm{~mL})$ were heated to reflux. $\mathrm{I}_{2}(10.00 \mathrm{mmol})$ was added, and the mix- ture was stirred at reflux for $10 \mathrm{~min}$. The mixture was filtered, and the precipitate washed with water $(20 \mathrm{~mL})$ to give phenazine 6 . The filtrate was washed with $\mathrm{Na}_{2} \mathrm{CO}_{3}$ (satd., $20 \mathrm{~mL}$ ) and $\mathrm{Na}_{2} \mathrm{~S}_{2} \mathrm{O}_{3}(1 \mathrm{M}, 20 \mathrm{~mL}$ ), and the organic extract was dried $\left(\mathrm{MgSO}_{4}\right)$ and evaporated to dryness. Benzimidazole 5d did not require purification. The residue of benzimidazole $\mathbf{5 a}$ was purified by column chromatography using gradient elution of petroleum ether/EtOAc.

6,9-Dimethoxy-3,4-dihydro-1H-[1,4]oxazino[4,3-a]benzimidazole (5a) $(0.112 \mathrm{~g}, 48 \%), R_{\mathrm{f}} 0.35$ (EtO Ac); and 1,4,6,9-tetramethoxyphenazine (6) (9 mg, 6\%). Spectral data and melting points for $\mathbf{5 a}$ and $\mathbf{6}$ were consistent with the above.

5,8-Dimethoxy-2,3-dihydro-1H-pyrrolo[1,2-a]benzimidazole (5d) $(0.201 \mathrm{~g}, 92 \%)$; off-white solid; spectral data and melting point consistent with the literature. ${ }^{14}$

General Procedure for the Synthesis of Quinones 1 and 2. Benzimidazole $(0.26 \mathrm{mmol})$ and PIFA $(0.447 \mathrm{~g}, 1.04 \mathrm{mmol})$ in $\mathrm{H}_{2} \mathrm{O}(29 \mathrm{~mL})$ and $\mathrm{MeOH}(0.75 \mathrm{~mL})$ were stirred at room temperature for $2 \mathrm{~h}$. The mixture was extracted with $\mathrm{CH}_{2} \mathrm{Cl}_{2}$ $(3 \times 40 \mathrm{~mL})$. The organic extracts were dried $\left(\mathrm{MgSO}_{4}\right)$, evaporated, and purified by column chromatography using gradient elution of petroleum ether/EtOAc and EtOAc/MeOH.

3,4-Dihydro-1H-[1,4]oxazino[4,3-a]benzimidazole-6,9-dione (1) (39 mg, 74\%); yellow solid; $R_{\mathrm{f}} 0.41$ (EtOAc); m.p. (decomp. $>165^{\circ} \mathrm{C}$ ); $v_{\max }$ (neat, $\mathrm{cm}^{-1}$ ) 2924, $1664(\mathrm{C}=0), 1584$, $1531,1475,1436,1379,1345,1317,1289,1225,1202$, $1112,1095,1066 ;{ }^{1} \mathrm{H}$ NMR ( $\left.400 \mathrm{MHz}, \mathrm{CDCl}_{3}\right) \delta: 6.68\left(\mathrm{AB}_{\mathrm{q}}, J\right.$ $=10.4 \mathrm{~Hz}, 2 \mathrm{H}), 4.99\left(\mathrm{~s}, 2 \mathrm{H}, 1-\mathrm{CH}_{2}\right), 4.44(\mathrm{t}, J=5.2 \mathrm{~Hz}, 2 \mathrm{H})$, $4.14(\mathrm{t}, J=5.2 \mathrm{~Hz}, 2 \mathrm{H}) ;{ }^{13} \mathrm{C}\left\{{ }^{1} \mathrm{H}\right\} \mathrm{NMR}\left(100 \mathrm{MHz}, \mathrm{CDCl}_{3}\right) \delta$ : $180.9,178.1$ (both C=0), 148.0, 141.2 (both C), 136.6, 135.8 (both $\mathrm{CH}$ ), $130.1(\mathrm{C}), 65.0\left(1-\mathrm{CH}_{2}\right), 63.3,44.7$ (both $\mathrm{CH}_{2}$ ); HRMS (ESI) $m / z[\mathrm{M}+\mathrm{H}]+\mathrm{C}_{10} \mathrm{H}_{9} \mathrm{~N}_{2} \mathrm{O}_{3}$ Calcd for 205.0613; Found 205.0623 .

1',2'-Dihydro-4'H-spiro[oxetane-3,3'-pyrido[1,2-a]benzimidazole]-6',9'-dione (2) (49 mg, 78\%); yellow oil; $R_{\mathrm{f}} 0.44$ (1:10 $\mathrm{MeOH} / \mathrm{EtOAc}$ ); $v_{\max }$ (neat, $\mathrm{cm}^{-1}$ ) 2929, 1661 (C=0), 1510, $1487,1446,1350,1270,1202,1132 ;{ }^{1} \mathrm{H} \operatorname{NMR}(400 \mathrm{MHz}$, $\left.\mathrm{CDCl}_{3}\right) \delta: 6.62\left(\mathrm{AB}_{\mathrm{q}}, J=10.4 \mathrm{~Hz}, 2 \mathrm{H}\right), 4.56\left(\mathrm{AB}_{\mathrm{q}}, J=6.2 \mathrm{~Hz}, 4 \mathrm{H}\right.$, $\left.\mathrm{OCH}_{2}\right), 4.38\left(\mathrm{t}, J=6.2 \mathrm{~Hz}, 2 \mathrm{H}, 1^{\prime}-\mathrm{CH}_{2}\right), 3.32\left(\mathrm{~s}, 2 \mathrm{H}, 4^{\prime}-\mathrm{CH}_{2}\right)$, $2.38\left(\mathrm{t}, J=6.2 \mathrm{~Hz}, 2 \mathrm{H}, 2^{\prime}-\mathrm{CH}_{2}\right) ;{ }^{13} \mathrm{C}\left\{{ }^{1} \mathrm{H}\right\}$ NMR $(100 \mathrm{MHz}$, $\mathrm{CDCl}_{3}$ ) $\delta: 181.1,178.2$ (both $\mathrm{C}=0$ ), 151.9, 149.9 (both C), 136.5, 136.0 (both $\mathrm{CH}), 130.2(\mathrm{C}), 80.5\left(\mathrm{OCH}_{2}\right), 41.7\left(1^{\prime}-\right.$ $\mathrm{CH}_{2}$ ), 37.2 (C), $34.4\left(4^{\prime}-\mathrm{CH}_{2}\right), 30.4\left(2^{\prime}-\mathrm{CH}_{2}\right)$; HRMS (ESI) $\mathrm{m} / \mathrm{z}$ $[\mathrm{M}+\mathrm{H}]+\mathrm{C}_{13} \mathrm{H}_{13} \mathrm{~N}_{2} \mathrm{O}_{3}$ Calcd for 245.0926; Found 245.0923.

\section{ASSOCIATED CONTENT}

Supporting Information. The supporting information is available free of charge via http://pubs.acs.org at DOI: XXXXXXX. GC-MS, ${ }^{1} \mathrm{H}$ and ${ }^{13} \mathrm{C}$ NMR spectra, and crystallographic data (PDF).

\section{AUTHOR INFORMATION}

\section{Corresponding Author}

*E-mail: f.aldabbagh@kingston.ac.uk

\section{Present Addresses}

$\S$ Department of Pharmacy, School of Life Sciences, Pharmacy and Chemistry, Kingston University, Penrhyn Road, Kingston upon Thames, KT1 2EE, UK. 
Notes

The authors declare no competing financial interest.

\section{ACKNOWLEDGMENT}

We thank Kingston University for a PhD studentship for Darren Conboy, and the Irish Research Council (IRC) for a Government of Ireland Postdoctoral Fellowship for Styliana I. Mirallai.

\section{REFERENCES}

(1) Vitaku, E.; Smith, D. T.; Njardarson, J. T. Analysis of the Structural Diversity, Substitution Patterns, and Frequency of Nitrogen Heterocycles among U.S. FDA Approved Pharmaceuticals. J. Med. Chem. 2014, 57, 1025710274.

(2) St. Jean Jr., D. J.; Fotsch, C. Mitigating Heterocycle Metabolism in Drug Discovery. J. Med. Chem. 2012, 55, 6002-6020.

(3) Arshad, F.; Khan, M. F.; Akhtar, W.; Alam, M. M.; Nainwal, L. M.; Kaushik, S. K.; Akhter, M.; Parvez, S.; Hasan, S. M.; Shaquiquzzaman, M. Revealing Quinquennial Anticancer Journey of Morpholine: A SAR Based Review. Eur. J. Med. Chem. 2019, 167, 324-356.

(4) Wuitschik, G.; Carreira, E. M.; Wagner, B.; Fischer, H.; Parrilla, I.; Schuler, F.; Rogers-Evans, M.; Müller, K. Oxetanes in Drug Discovery: Structural and Synthetic Insights. J. Med. Chem. 2010, 53, 3227-3246.

(5) Bull, J. A.; Croft, R. A.; Davis, O. A.; Doran, R.; Morgan, K. F. Oxetanes: Recent Advances in Synthesis, Reactivity, and Medicinal Chemistry. Chem. Rev. 2016, 116, 1215012233.

(6) Zhang, K.; Chen, D.; Ma, K.; Wu, X.; Hao, H.; Jiang, S. NAD(P)H:Quinone Oxidoreductase 1 (NQ01) as a Therapeutic and Diagnostic Target in Cancer. J. Med. Chem. 2018, 61, 6983-7003.

(7) Colucci, M. A.; Couch, G. D.; Moody, C. J. Natural and Synthetic Quinones and their Reduction by the Quinone Reductase Enzyme NQ01: From Synthetic Organic Chemistry to Compounds with Anticancer Potential. Org. Biomol. Chem. 2008, 6, 637-656.

(8) Newsome, J. J.; Colucci, M. A.; Hassani, M.; Beall, H. D.; Moody, C. J. Benzimidazole- and Benzothiazole-Quinones: Excellent Substrates for NAD(P)H:Quinone Oxidoreductase 1. Org. Biomol. Chem. 2007, 5, 3665-3673.

(9) Fagan, V.; Bonham, S.; Carty, M. P.; Saenz-Méndez, P.; Eriksson, L. A.; Aldabbagh, F. COMPARE Analysis of the Toxicity of an Iminoquinone Derivative of the Imidazo[5,4- $f$ ] benzimidazoles with NAD(P)H:Quinone Oxidoreductase 1 (NQ01) Activity and Computational Docking of Quinones as NQ01 Substrates. Bioorg. Med. Chem. 2012, 20, 3223-3232.

(10) Nair, M. D.; Adams, R. Benzimidazole Syntheses by Oxidative Cyclization with Peroxytrifluoroacetic Acid. J. Am. Chem. Soc. 1961, 83, 3518-3521.
(11) Meth-Cohn, 0.; Smalley R. K.; Suschitzky, H. Syntheses of Heterocyclic Compounds. Part III. Pyrolytic Cyclisation of Aromatic Azides. J. Chem. Soc. 1963, 16661669.

(12) Fahey, K.; Aldabbagh, F. Synthesis of Seven- and Eight-Membered [1,2-a] Alicyclic Ring-Fused Benzimidazoles and 3-Aziridinylazepino[1,2-a] benzimidazolequi none as a Potential Antitumour Agent. Tetrahedron Lett. 2008, 49, 5235-5237.

(13) Gurry, M.; Sweeney, M.; McArdle, P.; Aldabbagh, F. One-Pot Hydrogen Peroxide and Hydrohalic Acid Induced Ring Closure and Selective Aromatic Halogenation To Give New Ring-Fused Benzimidazoles. Org. Lett. 2015, 17, 2856-2859.

(14) Sweeney, M.; Gurry, M.; Keane, L.-A. J.; Aldabbagh, F. Greener Synthesis Using Hydrogen Peroxide in Ethyl Acetate of Alicyclic Ring-Fused Benzimidazoles and AntiTumour Benzimidazolequinones. Tetrahedron Lett. 2017, 58, 3565-3567.

(15) Sweeney, M.; Keane, L.-A. J.; Gurry, M.; McArdle, P.; Aldabbagh, F. One-Pot Synthesis of Dihalogenated RingFused Benzimidazolequinones from 3,6-Dimethoxy-2(cycloamino)anilines Using Hydrogen Peroxide and Hydrohalic Acid. Org. Lett. 2018, 20, 6970-6974.

(16) Parr, R. G.; Szentpály, L. v.; Liu, S. Electrophilicity Index. J. Am. Chem. Soc. 1999, 121, 1922-1924.

(17) Gurry, M.; McArdle, P.; Aldabbagh, F. Synthesis of a Spirocyclic Oxetane-Fused Benzimidazole. Molecules 2015, 20, 13864-13874.

(18) Alder, C. M.; Hayler, J. D.; Henderson, R. K.; Redman, A. M.; Shukla, L.; Shuster, L. E.; Sneddon, H. F. Updating and Further Expanding GSK's Solvent Sustainability Guide. Green Chem. 2016, 18, 3879-3890.

(19) Laursen, J. B.; Nielsen, J. Phenazine Natural Products: Biosynthesis, Synthetic Analogues, and Biological Activity. Chem. Rev. 2004, 104, 1663-1686.

(20) Guttenberger, N.; Blankenfeldt, W.; Breinbauer, R. Recent Developments in the Isolation, Biological Function, Biosynthesis, and Synthesis of Phenazine Natural Products. Bioorg. Med. Chem. 2017, 25, 6149-6166.

(21) Wohl, A.; Aue, W. Ueber die Einwirkung von Nitrobenzol auf Anilin bei Gegenwart von Alkali. Ber. Dtsch. Chem. Ges. 1901, 34, 2442-2450.

(22) Sugimoto, A.; Kato, S.; Inoue, H.; Imoto, E. Studies on Organic Semiconductors. XVIII. Photoconductivity of Heteroaromatic Compounds and Their Substituted Derivatives. Bull. Chem. Soc. Jpn. 1976, 49, 337-338.

(23) Wróbel, Z.; Stachowska, K.; Kwast, A. Phenazines and Their $\mathrm{N}$-Oxides as Products of Cyclization of $\mathrm{N}$-Aryl2-nitrosoanilines - Disproof of the Reported Homolytic Cross-Coupling Process Leading to Benzo[c]cinnoline Oxides. Eur. J. Org. Chem. 2014, 2014, 7721-7725.

(24) Bray, W. C.; Liebhafsky, H. A. Reactions Involving Hydrogen Peroxide, Iodine and Iodate Ion. I. Introduction. J. Am. Chem. Soc. 1931, 53, 38-44. 
(25) Schmitz, G. Iodine Oxidation by Hydrogen Peroxi de in Acidic Solutions, Bray-Liebhafsky Reaction and Other Related Reactions. Phys. Chem. Chem. Phys. 2010, 12, 6605-6615.

(26) Trummal, A.; Lipping, L.; Kaljurand, I.; Koppel, I. A.; Leito, I. Acidity of Strong Acids in Water and Dimethyl Sulfoxide. J. Phys. Chem. A 2016, 120, 3663-3669.

(27) Isse, A. A.; Lin, C. Y.; Coote, M. L.; Gennaro, A. Estimation of Standard Reduction Potentials of Halogen Atoms and Alkyl Halides. J. Phys. Chem. B 2011, 115, 678-684.

(28) Purkait, A.; Roy, S. K.; Srivastava, H. K.; Jana, C. K. Metal-Free Sequential $\mathrm{C}\left(\mathrm{sp}^{2}\right)-\mathrm{H} / \mathrm{OH}$ and $\mathrm{C}\left(\mathrm{sp}^{3}\right)-\mathrm{H}$ Aminations of Nitrosoarenes and $\mathrm{N}$-Heterocycles to RingFused Imidazoles. Org. Lett. 2017, 19, 2540-2543.

(29) Kwast, A.; Stachowska, K.; Trawczyński, A.; Wróbel, Z. $N$-Aryl-2-Nitrosoanilines as Intermediates in the Synthesis of Substituted Phenazines from Nitroarenes. Tetrahedron Lett. 2011, 52, 6484-6488.

(30) Fagan, V.; Bonham, S.; McArdle, P.; Carty, M. P.; Aldabbagh, F. Synthesis and Toxicity of New Ring-Fused Imidazo[5,4-f] benzimidazolequinones and Mechanism Using Amine N-Oxide Cyclizations. Eur. J. Org. Chem. 2012, 2012, 1967-1975.

(31) Meth-Cohn, O. Mechanism of Formation of Benzim idazoles by Oxidation of $o$-Acylamino- $N N$-Dialkylanilines with Peroxy-Acids. J. Chem. Soc. C 1971, 1356-1357.

(32) Meth-Cohn, 0 . The $t$-Amino Effect: Heterocycles Formed by Ring Closure of ortho-Substituted $t$-Anilines. In Adv. Heterocycl. Chem.; A. R. Katritzky, Ed.; Academic Press: San Diego, CA, 1996; Vol. 65, pp. 1-37.

(33) Nguyen, T. B.; Ermolenko, L.; Al-Mourabit, A. Formic Acid as a Sustainable and Complementary Reductant: An Approach to Fused Benzimidazoles by Molecular Iodine Catalyzed Reductive Redox Cyclization of $o$-Nitro-t-anilines. Green Chem. 2016, 18, 2966-2970.

(34) Ogata, Y.; Sawaki, Y.; Mibae, J.; Morimoto, T. Kinetics of the Autoxidation of Phenylhydroxylamines to Azoxybenzenes in Methanol. J. Am. Chem. Soc. 1964, 86, 3854-3858.

(35) Bamberger, E.; Ham, W. Über das Verhalten einiger parasubstituierter Nitrosobenzole gegen konz. Schwefelsäure. Ann. Chem. 1911, 382, 82-128.

(36) Seth, K.; Raha Roya, S.; Chakraborti, A. K. Synchronous Double C-N Bond Formation via C-H Activation for a Novel Synthetic Route to Phenazine. Chem. Commun. 2016, 52, 922-925.

(37) Tohma, H.; Morioka, H.; Harayama, Y.; Hashizume, M.; Kita, Y. Novel and Efficient Synthesis of $p$-Quinones in Water via Oxidative Demethylation of Phenol Ethers using Hypervalent Iodine(III) Reagents. Tetrahedron Lett. 2001, 42, 6899-6902.

(38) Nair, V.; Rajan, R.; Mohanan, K.; Sheeba, V. Cerium(IV) Ammonium Nitrate-Mediated Oxidative Rearrangement of Cyclobutanes and Oxetanes. Tetrahedron Lett. 2003, 44, 4585-4588.
(39) Loman, J. J.; Carnaghan, E. R.; Hamlin, T. A.; Ovian, J. M.; Kelly, C. B.; Mercadante, M. A.; Leadbeater, N. E. A Combined Computational and Experimental Investigation of the Oxidative Ring-Opening of Cyclic Ethers by Oxoammonium Cations. Org. Biomol. Chem. 2016, 14, 3883-3888.

(40) Hammershøj, P.; Reenberg, T. K.; Pittelkow, M.; Ni elsen, C. B.; Hammerich, O.; Christensen, J. B. Synthesis and Properties of 2,3-Dialkynyl-1,4-benzoquinones. Eur. J. Org. Chem. 2006, 2006, 2786-2794.

(41) Wang, G.-T.; Zhao, X.; Li, Z.-T. Hydrogen Bonded Arylamide-Linked Cholesteryl Dimesogenic Liquid Crystals: A Study of the Length and Side Chain Effects. Tetrahedron 2011, 67, 48-57.

(42) Sheldrick, G. M. SHELXT - Integrated Space-Group and Crys-tal-Structure Determination. Acta Crystallogr. Sect. A: Found. Adv. 2015, 71,3-8.

(43) Sheldrick, G. M. Crystal Structure Refinement with SHELXL. Acta Crystallogr. Sect. C: Struct. Chem. 2015, 71, 38.

(44) McArdle, P. Oscail, a Program Package for Small-Molecule Single-Crystal Crystallography with Crystal Morphology Prediction and Molecular Modelling. J. Appl. Crystallogr. 2017, 50, 320-326. 


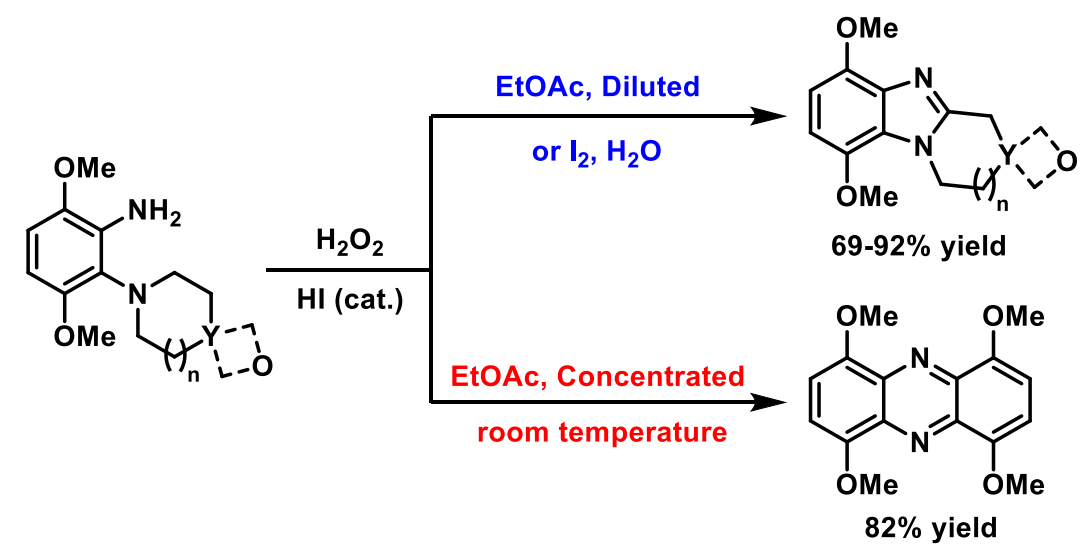

